Aude Belbezier, MD

Bastien Joubert, MD

Gonzalo Montero-

Martin, MSc

Marcelo Fernandez-Vina, $\mathrm{PhD}$

Nicole Fabien, MD

Véronique Rogemond, $\mathrm{PhD}$

Emmanuel Mignot, MD, $\mathrm{PhD}$

Jérôme Honnorat, MD, $\mathrm{PhD}$

Correspondence to

Dr. Honnorat:

jerome.honnorat@chu-lyon.fr

\section{Multiplex family with GAD65-Abs neurologic syndromes}

\section{OPEN}

\section{ABSTRACT}

Objective: Neurologic autoimmune syndromes associated with anti-glutamate acid decarboxylase 65 antibodies (GAD65-Abs) are rare and mostly sporadic.

Methods: We describe a niece and her aunt with GAD65-Abs neurologic syndromes. Highresolution HLA typing of Class I and Class II alleles was performed using next-generation sequencing.

Results: The proband had cerebellar ataxia and probable limbic encephalitis features, whereas her niece had stiff-person syndrome. Both had a high titer of GAD65-Abs in serum and CSF and showed signs of inflammation in CSF. Both affected members carried the same rare recombinant DRB1*15:01:01 DQA1*01:02:01 DQB1*05:02:01 haplotype, which may or may not be involved in disease susceptibility. Of interest, other unaffected members of the family either had the same HLA haplotype but normal serum GAD65-Abs or had different HLA types but a high titer of serum GAD65-Abs without neurologic symptoms, suggesting cumulative effects.

Conclusions: This unique association strengthens the concept that hereditary factors, possibly including specific HLA haplotypes, play a role in neurologic syndromes associated with GAD65Abs. Neurol Neuroimmunol Neuroinflamm 2018;5:e416; doi: 10.1212/NXI.0000000000000416

\section{GLOSSARY}

GAD = glutamic acid decarboxylase; IgG = immunoglobulin G; SPS = stiff-person syndrome; T1DM = type 1 diabetes mellitus; TG $=$ antithyroglobulin; TPO $=$ antithyroperoxidase.

Glutamic acid decarboxylase (GAD) is the rate-limiting enzyme for the production of $\gamma$-aminobutyric acid, the main inhibitory neurotransmitter of the CNS. GAD is also expressed in pancreatic islet $\beta$-cells. ${ }^{1}$ Anti-GAD65 antibodies (GAD65-Abs) have been described as a biological marker in patients with type 1 diabetes mellitus (T1DM), but also in some patients with neurologic diseases, such as stiff-person syndrome (SPS), cerebellar ataxia, or limbic encephalitis. ${ }^{2-7}$ Although rare, the concept of neurologic syndromes with GAD65-Abs is now well established, most cases reported so far being sporadic. ${ }^{8}$ Few experimental studies suggest a possible pathogenic role of GAD65-Abs. ${ }^{9-11}$ We describe 2 members of the same family with GAD65-Abs neurologic syndromes in combination with a rare recombinant HLA haplotype and 2 other members without the same haplotype and with a high level of GAD65-Abs but no neurologic symptoms. These results suggest that there may be a genetic basis for susceptibility of the development of GAD-antibody autoimmunity.

METHODS Written informed consent was obtained from all HLA-tested members, and this study was approved by the Institutional Review Board of University Claude Bernard Lyon 1 and Hospices Civils de Lyon. Samples are deposited in the collection of biological

From the French Reference Center on Paraneoplastic Neurological Syndrome (A.B., B.J., V.R., J.H.), Hospices Civils de Lyon, Hôpital Neurologique, Bron, France; Institut NeuroMyoGene INSERM U1217/CNRS UMR 5310 (A.B., B.J., V.R., J.H.), Université de Lyon-Université Claude Bernard Lyon 1, France; Stanford Blood Center (G.M.-M., M.F.-V., E.M.), Histocompatibility, Immunogenetics \& Disease Profiling Laboratory, Palo Alto, CA; Immunology, Hospices Civils de Lyon (N.F.), Hôpital Lyon-Sud, France; and Stanford University Center for Sleep Sciences and Medicine (E.M), Palo Alto, CA.

Funding information and disclosures are provided at the end of the article. Go to Neurology.org/nn for full disclosure forms. The Article Processing Charge was funded by the ADR05 INSERM, France.

This is an open access article distributed under the terms of the Creative Commons Attribution-NonCommercial-NoDerivatives License 4.0 (CC BY-NC-ND), which permits downloading and sharing the work provided it is properly cited. The work cannot be changed in any way or used commercially without permission from the journal. 
samples named "Neurobiotec" registered as the biobank of the Hospices Civils de Lyon. Full HLA next-generation sequencingbased typing was performed based on long-range PCRs detailed by Wang in $2012 .{ }^{12}$

RESULTS Cases reports. The first patient (II3, figure), a 68-year-old woman without a medical history, first developed acute dizziness and vomiting. Neurologic clinical examination revealed an ataxic gait with enlargement of the sustentation polygon and nystagmus. The rest of the physical examination was normal. Videonystagmography revealed a left vestibular deficit. Brain MRI showed no cerebellar atrophy, but hypersignal intensity on fluid attenuation inversion recovery sequences restricted to both hippocampi (nevertheless, no acute clinical signs of limbic encephalitis were observed). CSF examination showed elevated protein levels at $0.71 \mathrm{~g} / \mathrm{L}$ without white blood cells and a normal immunoglobulin $\mathrm{G}$ (IgG) index $(0.5$; normal $<0.7)$, but few oligoclonal bands $(<5)$ were present. GAD65-Abs were positive in CSF at $250 \mathrm{IU} / \mathrm{mL}$ as well as in the serum above 1,200 IU/mL (ELISA Medipan, cutoff positivity: 5 $\mathrm{IU} / \mathrm{mL}$ ). Antithyroperoxidase (TPO) and antithyroglobulin (TG) antibodies were also positive (Varelisa; Thermo Fischer Scientific, Waltham, MA) (718 and $283 \mathrm{IU} / \mathrm{mL}$, respectively, cutoff of positivity for both Abs: $60 \mathrm{IU} / \mathrm{mL}$ ). No other biological abnormalities were detected. Body fluorodeoxyglucosePET and mammography were also normal. A diagnosis of cerebellar ataxia with GAD65-Abs was

Figure Family tree with the HLA haplotyping of 6 members of the family

A

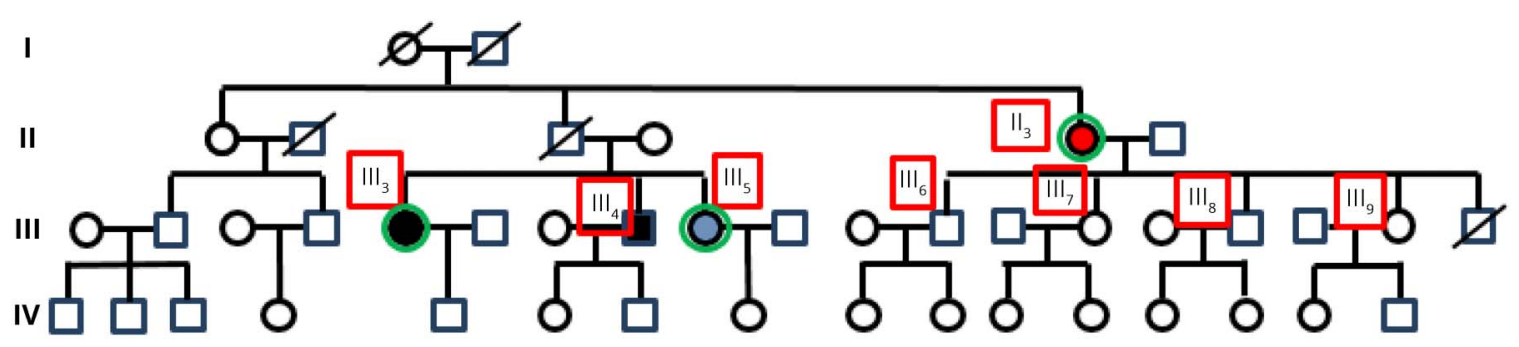

Patient with anti-GAD antibodies without neurologic syndrome

Patient with anti-GAD antibodies and cerebellar ataxia

Patient with anti-GAD antibodies and stiff-person syndrome

Patient with anti-TPO antibodies

B

\begin{tabular}{|c|c|c|c|c|c|c|}
\hline Subjects & $A / 1$ & $\mathrm{~A} / 2$ & $B / 1$ & $B / 2$ & $\mathrm{C} / 1$ & $\mathrm{C} / 2$ \\
\hline 113 & $A * 24: 02: 01: 01$ & $A^{\star} 01: 01: 01: 01$ & $B * 39: 06: 02$ & $B^{\star} 08: 01: 01$ & $C^{\star} 07: 02: 01: 01$ & $C^{*} 07: 01: 01: 01$ \\
\hline 1115 & $A * 24: 02: 01: 01$ & $A^{*} 11: 01: 01: 01$ & $B * 39: 06: 02$ & $B * 35: 02: 01$ & $C^{\star} 07: 02: 01: 01$ & $C^{*} 04: 01: 01: 06$ \\
\hline 1113 & $A^{* 11: 01: 01: 01}$ & $A^{*} 02: 01: 01: 01$ & $B * 52: 01: 01: 02$ & $B * 35: 08: 01$ & $C * 12: 02: 02$ & $C^{*} 04: 01: 01: 06$ \\
\hline|| $\mid 4$ & $A^{* 11: 01: 01: 01}$ & $A^{* 11: 01: 01: 01}$ & $B * 52: 01: 01: 02$ & $B * 35: 02: 01$ & $C * 12: 02: 02$ & $C^{*} 04: 01: 01: 06$ \\
\hline 1116 & $A^{*} 24: 02: 01: 01$ & $A^{*} 02: 01: 01: 01$ & $B * 39: 06: 02$ & $B * 44: 05: 01$ & $C^{*} 07: 02: 01: 01$ & $C^{*} 02: 02: 02: 01$ \\
\hline 1117 & $A^{*} 24: 02: 01: 01$ & $A^{*} 02: 01: 01: 01$ & $B * 39: 06: 02$ & $B^{*} 44: 02: 01: 01$ & $C * 07: 02: 01: 01$ & $C * 05: 01: 01: 02$ \\
\hline 1118 & $A * 24: 02: 01: 01$ & $A^{\star} 02: 01: 01: 01$ & $B * 39: 06: 02$ & $B * 44: 05: 01$ & $C^{\star} 07: 02: 01: 01$ & $C^{*} 02: 02: 02: 01$ \\
\hline 1119 & $A * 24: 02: 01: 01$ & $A^{\star} 02: 01: 01: 01$ & $B * 39: 06: 02$ & $B * 44: 02: 01: 01$ & $C \star 07: 02: 01: 01$ & $C * 05: 01: 01: 02$ \\
\hline
\end{tabular}

\begin{tabular}{|c|c|c|c|c|c|c|}
\hline Subjects & DPA1/1 & DPA1/2 & DPB1/1 & DPB1/2 & DQA1/1 & DQA1/2 \\
\hline 113 & DPA1*01:03:01:05 & DPA1*02:01:02 & DPB1*04:02:01:02 & DPB1*01:01:01 & DQA1*01:02:01:03 & DQA1*05:01:01:02 \\
\hline 1115 & DPA1*01:03:01:05 & DPA1*01:03:01:03 & DPB1*04:02:01:02 & DPB1*03:01:01 & DQA1*01:02:01:03 & DQA1*05:05:01:01 \\
\hline 1113 & DPA $1 * 02: 02: 01$ & DPA $1 * 02: 02: 02$ & DPB1*04:01:01:01 & DPB1*05:01:01 & DQA1*01:03:01:01 & DQA1*05:05:01:01 \\
\hline$\| 114$ & DPA $1 * 02: 02: 01$ & DPA $1 * 01: 03: 01: 03$ & DPB1*04:01:01:01 & DPB1*03:01:01 & DQA1*01:03:01:01 & DQA1*05:05:01:01 \\
\hline 1116 & DPA1*01:03:01:05 & DPA1*01:03:01:02 & DPB1*04:02:01:02 & DPB1*02:01:02 & DQA1*01:02:01:03 & DQA $1 * 01: 02: 02$ \\
\hline III7 & DPA1*01:03:01:05 & DPA1*02:01:01 & DPB1*04:02:01:02 & DPB1*14:01:01 & $\mathrm{DQA1} * 01: 02: 01: 03$ & DQA1*01:03:01:02 \\
\hline 1118 & DPA1*01:03:01:05 & DPA $1 * 01: 03: 01: 02$ & DPB1*04:02:01:02 & DPB $1 * 02: 01: 02$ & DQA1*01:02:01:03 & DQA $1 * 01: 02: 02$ \\
\hline 1119 & DPA1*01:03:01:05 & DPA $1 * 02: 01: 01$ & DPB1*04:02:01:02 & DPB1*14:01:01 & DQA1*01:02:01:03 & DQA1*01:03:01:02 \\
\hline Subjects & DQB1/1 & DQB1/2 & DRB1/1 & DRB1/2 & DRBo/1 & $\mathrm{DRBo} / 2$ \\
\hline 113 & $\mathrm{DQB} 1 * 05: 02: 01$ & DQB1*02:01:01 & DRB1*15:01:01:03 & DRB1*03:01:01:01 & DRB5*01:01:01 & $\mathrm{DRB}^{*} 01: 01: 02: 01$ \\
\hline 1115 & DQB1*05:02:01 & DQB1*03:01:01:02 & DRB1*15:01:01:03 & DRB1*11:04:01 & DRB5*01:01:01 & DRB3*02:02:01:02 \\
\hline 1113 & DQB1*06:01:01 & DQB1*03:01:01:03 & DRB1*15:02:01 & DRB1*11:01:01 & DRB5*01:02 & DRB3*02:02:01:02 \\
\hline 1114 & DQB1*06:01:01 & DQB1*03:01:01:02 & DRB1*15:02:01 & DRB1*11:04:01 & DRB5*01:02 & DRB3*02:02:01:02 \\
\hline 1116 & DQB1*05:02:01 & DQB1*05:02:01 & DRB1*15:01:01:03 & DRB1*16:01:01 & DRB5*01:01:01 & DRB5*02:02 \\
\hline 1117 & DQB1*05:02:01 & $D Q B 1 * 06: 03: 01$ & DRB1*15:01:01:03 & DRB1*13:01:01 & DRB5*01:01:01 & DRB3*01:01:02:01 \\
\hline 1118 & DQB1*05:02:01 & $\mathrm{DQB1*} 05: 02: 01$ & DRB1*15:01:01:03 & DRB1*16:01:01 & DRB5*01:01:01 & DRB5*02:02 \\
\hline 1119 & $\mathrm{DQB1*05:02:01}$ & DQB1*06:03:01 & DRB1*15:01:01:03 & DRB1*13:01:01 & DRB5*01:01:01 & $\mathrm{DRB3}^{* 01: 01: 02: 01}$ \\
\hline
\end{tabular}

The colors indicate the bioclinical characteristics of the patients. Black circle: patients with GAD65-Abs without neurologic syndromes (III3 and III4). Red circle: patient with GAD65-Abs and cerebellar ataxia (II3). Blue circle: patient with GAD65-Abs and stiff-person syndrome (III5). Green circle: patients with TPO-Abs (II3, III3, and III5). 
proposed, and treatment with monthly IV immunoglobulin was initiated. After 6 months, the patient stabilized, while still exhibiting a mild cerebellar syndrome. GAD65-Abs remained positive during 15 years of follow-up. Brain MRI performed 4 years after onset showed cerebellar and diffuse brain atrophy. The patient developed late-onset T1DM and a progressive dementia without significant clinical progression of cerebellar ataxia. HLA typing revealed the presence of an unusual haplotype DRB5*01:01:01 DRB1*15:01: 01 DQA1*01:02:01 〜DQB1*05:02:01, together with a classical type 1 diabetes-associated haplotype DRB1*03:01:01 DQA1*05:01:01 DQB1*02:01: 01 (figure). $\quad \mathrm{DRB} 5 * 01: 01: 01 \sim \mathrm{DRB} 1 * 15: 01$ : $01 \sim$ DQA1*01:02:01 $\sim \mathrm{DQB} 1 * 05: 02: 01$ is very unusual. In large samples from north European countries, the frequency is typically below 1 for 1,000 patients. We identified no patient with this haplotype in more than 100 French people. In our estimation, the frequency of this haplotype in France must be less than 1 for 5,000 patients.

Her niece (III5, figure) developed signs of progressive muscular rigidity with superimposed spasms at the age of 42 years. The right leg was first affected, followed by the trunk and the left leg. Her medical history was notable for Hashimoto thyroiditis (with anti-TPO at $1,966 \mathrm{IU} / \mathrm{mL}$ and anti-TG-Abs at $12,786 \mathrm{IU} / \mathrm{mL}$ ). Medullary and brain MRI were normal. The CSF study revealed a normal $\mathrm{IgG}$ index $(0.61$; normal $<0.7)$ with many oligoclonal bands $(>5)$ and GAD65-Abs at $250 \mathrm{IU} / \mathrm{mL}$. Serum GAD65-Abs were also positive with a titer above 2,000 IU/mL. EMG confirmed the suspicion of SPS with continuous motor activity and cocontraction of agonist and antagonist muscles of the thigh, hip, and back muscles. Five years later, no diabetes mellitus was observed and no cancer has been found. The patient has been treated with benzodiazepines, immunoglobulins, and cyclophosphamide and experienced only partial recovery. HLA typing revealed that this patient also carried the unusual DRB5*01:01:01 DRB1*15:01:01 DQA1*01:02: 01 DQB1*05:02:01 haplotype, together with DRB3*02:02:01 DRB1*11:04:01 DQA1*05:05: 01 DQB1*03:01:01 (figure).

Familial history. After identification of these 2 index cases, we reviewed the entire family history and extended HLA typing to 6 other members of the family (figure). The entire family is of Caucasian ethnicity. The father of II3 developed dementia and diabetes mellitus, but we have no more information. Of interest, 2 relatives (III3 and III4) without the rare DRB5*01:01:01 $\sim \mathrm{DRB}^{*}$ 15:01:01 DQA1*01:02: 01, $\sim \mathrm{DQB1} * 05: 02: 01$ haplotype had serum GAD65-Abs titer higher than $250 \mathrm{IU} / \mathrm{mL}$. One (III3), the sister of the patient III5 with SPS, developed pernicious anemia with intrinsic antibodies, breast cancer, and thyroiditis, and her brother (III4) had no particular medical history. All the members of the family were examined by $\mathrm{JH}$ and had no abnormalities on neurologic examination. No other disease was reported in the other members of the family. Conversely, 4 other members of the family (III 6, 7, 8, and 9) shared the rare DRB5*01:01:01 DRB1*15:01: 01 DQA1*01:02:01 DQB1*05:02:01 haplotype but had no GAD65-Abs and no neurologic symptoms. The father of II3 developed dementia and diabetes mellitus, and his HLA haplotype was not characterized.

DISCUSSION Very little is known regarding genetic predisposition to autoimmune neurologic syndromes with GAD65-Abs. HLA genetic predisposition to SPS has been studied only in 1 large study of 18 patients, with unremarkable findings, although weak association with DQB1*02 (DQB1*02:01 and DQB1*02:02) was suggested. ${ }^{13}$ In this study, however the presence of DQB1*06:02, a strong protective allele for type 1 diabetes, was present in some patients with SPS without type 1 diabetes but in none with cooccurring diabetes. ${ }^{13,14}$ However, a few familial occurrences of neurologic conditions associated with GAD65-Abs have been previously described, 2 families with multiplex familial SPS ${ }^{15,16}$ and 1 family with 2 sibling sisters with cerebellar ataxia and GAD65-Abs, ${ }^{17}$ suggesting that genetic factors may be involved (HLA typing was not performed in these cases).

In our 2 cases, DQB1*02 was present only in 1 affected case, but both carried an unusual haplotype HLA-DRB1* 15:01 DQA1*01:02 DQB1*05:02. This haplotype is likely the result from recombination of HLA DRB1*15:01:01 DQA1*01:02:01 $\sim$ DQB1*06:02:01 with DRB1*16:01/2 DQA1 *01:02:02 DQB1*05:02:01, 2 common Caucasian haplotypes. We can also speculate that the father of II3 who developed dementia and diabetes mellitus may also have had this rare haplotype. Although reported rarely in the literature, except in a few patients of Romani people, Northern Indian, and Chinese origin, ${ }^{18-20}$ this haplotype is extremely rare in US and French Caucasians $(<0.1 \%)^{21}$ and thus unlikely to be present by chance in these 2 affected patients. ${ }^{20}$ The rare haplotype, if involved, is however not the sole determinant of disease, as 4 relatives (III 6, 7, 8, and 9) with the haplotype do not have neurologic symptoms or GAD65-Abs.

Surprisingly, we also found 2 other relatives (III3 and III4) having high GAD65-Abs titers without neurologic symptoms. This is also unlikely to be a chance phenomenon, as GAD65-Abs are found only in around $1.7 \%$ of the general population with or without neurologic disorders. ${ }^{22,23}$ Of interest, the 
presence of GAD65-Abs in the general asymptomatic population (including asymptomatic individuals from families with prevalent type 1 diabetes) also correlates with typical type 1 diabetes-associated HLA DRB1*03:01 DQA1*05:01 DQB1*02:01 and DRB1*04 DQA $1 * 03 \sim \mathrm{DQB} 1 * 03: 02$, notably when both haplotypes are in trans of each other. ${ }^{23,24}$ In our family, the 2 asymptomatic patients with high GAD65-Abs do not share the same extended HLA subtypes with both affected patients, suggesting that GAD65-Abs are unlinked with HLA alone and that the sole presence of high titers of GAD65-Abs is insufficient to develop neurologic symptoms. One reason could be that GAD65-Abs in affected vs unaffected patients target different epitopes, as has been shown for type 1 diabetes vs SPS. ${ }^{25-27}$ Of interest, a recent study in 6,556 type 1 diabetes cases has shown strong genetic association for the presence of GAD65-Abs not with an HLA region, but with other genes, notably in IFIH1, a locus associated with positivity for TPO and GAD65-Abs ${ }^{28}$ and involved in other immune phenotypes. ${ }^{29,30}$

A similar complex genetic susceptibility has already been discussed in neuromyelitis optica (NMO), another autoimmune neurologic disorder associated with antineural antibodies. ${ }^{31}$ In NMO, around 3\% of patients have a familial occurrence of the disease, and familial $\mathrm{NMO}$ is indistinguishable from sporadic NMO. ${ }^{31}$ Furthermore, the association with a specific HLA haplotyping is also highly debated..$^{32}$ Our family with GAD65-Abs and all the data of the literature suggest that coincident complex genetic factors in the HLA and non-HLA regions should be carefully studied in autoimmune neurologic disorders associated with antineural antibodies.

\section{AUTHOR CONTRIBUTIONS}

Aude Belbezier contributed to the acquisition of data, analysis, interpretation of the data, drafting the manuscript for intellectual contents. Bastien Joubert contributed to the acquisition of data, analysis, interpretation of the data, critical revision of the manuscript for intellectual content. Gonzalo Montero-Martin contributed to the acquisition of data, analysis, interpretation of the data, critical revision of the manuscript for intellectual content. Marcelo Fernandez-Vina contributed to the acquisition of data, analysis, interpretation of the data, critical revision of the manuscript for intellectual content. Nicole Fabien contributed to the acquisition of data. Véronique Rogemond contributed to the acquisition of data. Emmanuel Mignot contributed to the interpretation of the data and critical revision of the manuscript for intellectual content. Jérôme Honnorat contributed to the study concept and design of the study, critical revision of manuscript for intellectual content, study supervision.

\section{ACKNOWLEDGMENT}

The authors thank Dr. Michel Gouttard for his help to collect clinical data.

\section{STUDY FUNDING}

This study is supported by research grants from ANR (ANR-14-CE150001-MECANO), the Federation pour la recherche sur le cerveau (FRC-Neurodon2014), the Fondation pour la Recherche Médicale (Programme “équipe FRM” DEQ20170336751), and CSL Behring France.

\section{DISCLOSURE}

A. Belbezier, B. Joubert, and G. Montero-Martin report no disclosures. M. Fernandez-Vina serves on the editorial board of Human Immunology and received research support from NIH-NIAID. N. Fabien and V. Rogemond report no disclosures. E. Mignot served on the scientific advisory board of FDA, Kleine-Levin Syndrome Foundation, National Academy of Sciences, Institute of Medicine, Board on Neuroscience and Behavioral Health, Study Task Force on Sleep Research and Member, Membership Committee Section, NIH/NIMH, National Advisory Mental Health Council, Mood Disorders Workgroup, Board of Scientific Counselors, and Restless Leg Syndrome Foundation; served on the editorial board of Journal of Neuropsychopharmacology, Public Library of Sciences-Biology, Sleep, Sleep Medicine, Sleep Research Online, and Molecular Biology; receives publishing royalties from Informa Healthcare; consulted for Jazz Pharmaceuticals; received research support from GlaxoSmithKline, Novo Nordisk, Jazz Pharmaceuticals, NIH, National Institute of Neurological Disorders and Stroke, NSBRI, CORI, NASA, and HHMI; and held stock in ResMed. J. Honnorat served on the scientific advisory board of Bristol-Myers Squibb; holds patent for and receives royalties from licensing fees to Athena Diagnostics, Euroimmun, and Ravo Diagnostika for a patent for the use of CV2/CRMP5 as diagnostic tests; and received research support from CSL Behring France. Go to Neurology. $\mathrm{org} / \mathrm{nn}$ for full disclosure forms.

Received May 23, 2017. Accepted in final form October 2, 2017.

\section{REFERENCES}

1. Solimena M, Folli F, Aparisi R, et al. Autoantibodies to GABA-ergic neurons and pancreatic beta cells in stiff-man syndrome. N Engl J Med 1990;322:1555-1560.

2. Saiz A, Blanco Y, Sabater L, et al. Spectrum of neurological syndromes associated with glutamic acid decarboxylase antibodies: diagnostic clues for this association. Brain J Neurol 2008;131:2553-2563.

3. Honnorat J, Saiz A, Giometto B, et al. Cerebellar ataxia with anti-glutamic acid decarboxylase antibodies: study of 14 patients. Arch Neurol 2001;58:225-230.

4. Malter MP, Elger CE, Surges R. Diagnostic value of CSF findings in antibody-associated limbic and anti-NMDARencephalitis. Seizure 2013;22:136-140.

5. Falip M, Carreño M, Miró J, et al. Prevalence and immunological spectrum of temporal lobe epilepsy with glutamic acid decarboxylase antibodies. Eur J Neurol 2012;19:827-833.

6. Peltola J, Kulmala P, Isojärvi J, et al. Autoantibodies to glutamic acid decarboxylase in patients with therapyresistant epilepsy. Neurology 2000;55:46-50.

7. Tilikete C, Vighetto A, Trouillas P, et al. Potential role of anti-GAD antibodies in abnormal eye movements. Ann NY Acad Sci 2005;1039:446-454.

8. Dayalu P, Teener JW. Stiff Person syndrome and other anti-GAD-associated neurologic disorders. Semin Neurol 2012;32:544-549.

9. Manto MU, Laute MA, Aguera M, et al. Effects of antiglutamic acid decarboxylase antibodies associated with neurological diseases. Ann Neurol 2007;61:544-551.

10. Manto M, Honnorat J, Hampe CS, et al. Disease-specific monoclonal antibodies targeting glutamate decarboxylase impair GABAergic neurotransmission and affect motor learning and behavioral functions. Front Behav Neurosci 2015;9:78.

11. Gresa-Arribas N, Ariño H, Martínez-Hernández E, et al. Antibodies to inhibitory synaptic proteins in neurological syndromes associated with glutamic acid decarboxylase autoimmunity. PLoS One 2015;10:e0121364.

12. Wang C, Krishnakumar S, Wilhelmy J, et al. High-throughput, high-fidelity HLA genotyping with deep sequencing. Proc Natl Acad Sci USA 2012;109:8676-8681. 
13. Pugliese A, Solimena M, Awdeh ZL, et al. Association of HLA-DQB1*0201 with stiff-man syndrome. J Clin Endocrinol Metab 1993;77:1550-1553.

14. Pugliese A, Gianani R, Eisenbarth GS, et al. Genetics of susceptibility and resistance to insulin-dependent diabetes in stiff-man syndrome. Lancet 1994;344:1027-1028.

15. Burns TM, Jones HR, Phillips LH, et al. Clinically disparate stiff-person syndrome with GAD65 autoantibody in a father and daughter. Neurology 2003;61:1291-1293.

16. Xiao Z, Shan J, Huang X, et al. Familial case reports of stiff-person syndrome. Clin Neurophysiol 2015;126: 2408-2409.

17. Kuchling J, Shababi-Klein J, Nümann A, et al. GAD antibody-associated late-onset cerebellar ataxia in two female siblings. Case Rep Neurol 2014;6:264-270.

18. Rani R, Fernandez-Viña MA, Stastny P. Associations between HLA class II alleles in a North Indian population. Tissue Antigens 1998;52:37-43.

19. Cerná M, Fernandez-Viña M, Ivásková E, et al. Comparison of HLA class II alleles in Gypsy and Czech populations by DNA typing with oligonucleotide probes. Tissue Antigens 1992;39:111-116.

20. Han F, Lin L, Li J, et al. HLA-DQ association and allele competition in Chinese narcolepsy. Tissue Antigens 2012; 80:328-335.

21. Gragert L, Madbouly A, Freeman J, et al. Six-locus high resolution HLA haplotype frequencies derived from mixed-resolution DNA typing for the entire US donor registry. Hum Immunol 2013;74:1313-1320.

22. Dahm L, Ott C, Steiner J, et al. Seroprevalence of autoantibodies against brain antigens in health and disease. Ann Neurol 2014;76:82-94.

23. Sørgjerd EP, Thorsby PM, Torjesen PA, et al. Presence of anti-GAD in a non-diabetic population of adults; time dynamics and clinical influence: results from the HUNT study. BMJ Open Diabetes Res Care 2015;3:e000076.

24. Rolandsson O, Hägg E, Janer M, et al. High GAD65 autoantibody levels in nondiabetic adults are associated with HLA but not with CTLA-4 or INS VNTR. J Intern Med 2003;253:447-453.

25. Kim J, Namchuk M, Bugawan T, et al. Higher autoantibody levels and recognition of a linear NH2-terminal epitope in the autoantigen GAD65, distinguish stiff-man syndrome from insulin-dependent diabetes mellitus. J Exp Med 1994;180:595-606.

26. Chéramy M, Hampe CS, Ludvigsson J, et al. Characteristics of in-vitro phenotypes of glutamic acid decarboxylase 65 autoantibodies in high-titre individuals. Clin Exp Immunol 2013;171:247-254.

27. Lohmann T, Londei M, Hawa M, et al. Humoral and cellular autoimmune responses in stiff person syndrome. Ann NY Acad Sci 2003;998:215-222.

28. Brorsson CA, Pociot F; Type 1 Diabetes Genetics Consortium. Shared genetic basis for type 1 diabetes, islet autoantibodies, and autoantibodies associated with other immune-mediated diseases in families with type 1 diabetes. Diabetes Care 2015;38(suppl 2):S8-S13.

29. Bronson PG, Chang D, Bhangale T, et al. Common variants at PVT1, ATG13-AMBRA1, AHI1 and CLEC16A are associated with selective IgA deficiency. Nat Genet 2016;48:1425-1429.

30. Melki I, Crow YJ. Novel monogenic diseases causing human autoimmunity. Curr Opin Immunol 2015;37:1-5.

31. Matiello M, Kim HJ, Kim W, et al. Familial neuromyelitis optica. Neurology 2010;75:310-315.

32. Zéphir H, Fajardy I, Outteryck $\mathrm{O}$, et al. Is neuromyelitis optica associated with human leukocyte antigen? Mult Scler 2009; 15:571-579. 


\section{Neurology \\ Neuroimmunology \& Neuroinflammation}

Multiplex family with GAD65-Abs neurologic syndromes Aude Belbezier, Bastien Joubert, Gonzalo Montero-Martin, et al.

Neurol Neuroimmunol Neuroinflamm 2018;5;

DOI 10.1212/NXI.0000000000000416

This information is current as of December 6, 2017

Updated Information \& Services

References

Subspecialty Collections

Permissions \& Licensing

Reprints including high resolution figures, can be found at: http://nn.neurology.org/content/5/1/e416.full.html

This article cites 32 articles, 3 of which you can access for free at: http://nn.neurology.org/content/5/1/e416.full.html\#\#ref-list-1

This article, along with others on similar topics, appears in the following collection(s):

Autoimmune diseases

http://nn.neurology.org//cgi/collection/autoimmune_diseases

Information about reproducing this article in parts (figures,tables) or in its entirety can be found online at:

http://nn.neurology.org/misc/about.xhtml\#permissions

Information about ordering reprints can be found online: http://nn.neurology.org/misc/addir.xhtml\#reprintsus

Neurol Neuroimmunol Neuroinflamm is an official journal of the American Academy of Neurology.

Published since April 2014, it is an open-access, online-only, continuous publication journal. Copyright

Copyright (C) 2017 The Author(s). Published by Wolters Kluwer Health, Inc. on behalf of the American Academy of Neurology.. All rights reserved. Online ISSN: 2332-7812.

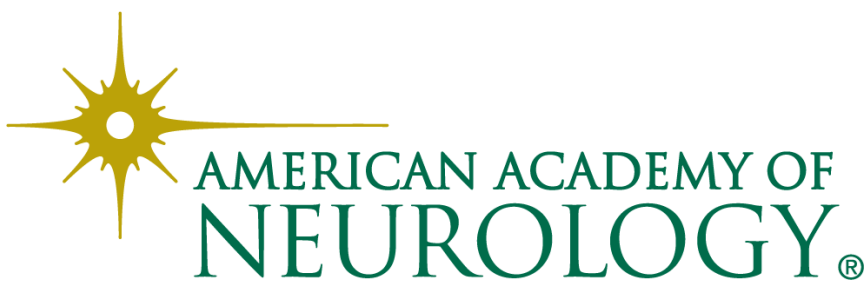

